\title{
DEPRESSIVE SYMPTOMS AND LEVEL OF 25-HYDROXYVITAMIN D IN FREE-LIVING OLDEST OLD
}

\author{
M.T. da Rocha Lima', O. Custódio², P. Ferreira do Prado Moreira ${ }^{3}$ L.M. Quirino Araujo², \\ C. de Mello Almada Filho ${ }^{2}$ M. Seabra Cendoroglo ${ }^{4}$
}

\begin{abstract}
Background: Nowadays, the relation between hypovitaminosis D and depression has been reported and it is estimated that 1 billion people worldwide have vitamin D deficiency or insufficiency. However, the oldest old people are not included or are under-represented in most of the studies. Objective: To examine the association between depressive symptoms and 25-hydroxyvitamin D level $(25(\mathrm{OH})$ Vit $\mathrm{D})$ in elderly aged 80 and over who are physically more active and independent. Design: Cross-sectional study. Setting and Participants: Data collected from 182 oldest old people, aged 80 and over in the Geriatric Division from Federal University of São Paulo. Measurements: The functionality was evaluated by the Instrumental activities of their daily living (IADL). The approach of the depressive symptoms was done by the Geriatric Depression Scale (GDS) in its reduced 15 item version. 25-hydroxyvitamin D $(25(\mathrm{OH})$ Vit $\mathrm{D})$ analyses was done in serum sample refrigerated and protected from solar exposition. We considered deficiency serum level of $25(\mathrm{OH})$ Vit $\mathrm{D}<10 \mathrm{ng} / \mathrm{mL}$, insufficiency between 10 and 30ng/mL and sufficiency $>30 \mathrm{ng} /$ mL. Results: According to blood level of 25(OH)Vit D we found difference between GDS score comparing the groups: "deficiency" $(\mathrm{U}=144,50 ; \mathrm{z}=-3,126 ; \mathrm{p}=0,002)$ and "insufficiency" groups $(\mathrm{U}=975,50 ; \mathrm{z}=-2,793 ; \mathrm{p}=0.005)$ are different than "sufficiency" group. Conclusion: In free-living independent oldest old people the goal of 25(OH)Vit D levels can be higher to avoid depressive symptoms, levels under 30ng/mL can be inadequate. Considering that the costs are low and side effects are not common, 25(OH) Vit D supplementation can be an important public health action.
\end{abstract}

Key words: Oldest old, aged, 80 and over, vitamin D, depression.

\section{Introduction}

The accelerated aging of Brazil has one of its epidemiologic consequences: the increased number of elderly with chronic diseases and incapacities that generate dependency (1). Late-life depression (LLD) affects from $10 \%$ to $22 \%$ of the growing geriatric population living in the community $(2,3)$, it's a risk factor for all-cause mortality in the elderly (4) and adults 85 and older appear to be more vulnerable to depression than other age groups (5). Wu et al. (6) demonstrates that the age-related growth of depressive symptoms occurs wholly in the context of medical comorbidity and does not have an independent effect. Weyerer et al. (7) found that the incidence of depression symptoms, measured using the GDS-15 Geriatric Depression Scale,

1. Geriatrics Division, Paulista School of Medicine, Federal University of Sao Paulo, Brazil; 2. Geriatrics Division, Paulista School of Medicine, Federal University of Sao Paulo, Brazil; 3. Nutritionist at the Geriatrics Division, Paulista School of Medicine, Federal University of Sao Paulo, Brazil; 4. Professor at the Geriatrics Division, Paulista School of Medicine, Federal University of Sao Paulo, Brazil

Corresponding Author: Márcio Tomita da Rocha Lima, Rua Professor Francisco de Castro, 105, Vila Clementino, CEP 04020-050, São Paulo - São Paulo, Brazil, Telephone number: +551155764848 - extension line 2298, marciotrl@yahoo.com.br increases significantly with age in non-demented primary care attenders aged 75 years and older. The presence of depressive symptoms as a risk factor for disability occurs in both genders (8) and it is associated with development of cognitive decline in older patients (9).

Nowadays, the relation between hypovitaminosis D and depression has been reported and it is estimated that 1 billion people worldwide have vitamin $D$ deficiency or insufficiency (10). Hoogendijk et al. (11), in a cohort study, found that the lower levels of vitamin $\mathrm{D}$ were associated with higher intensity of depression. Milaneschi et al. (12), in 2010, also in a cohort study (InCHIANTI study), evaluated elderly of ages 65 and up and observed that hypovitaminosis D was a risk factor for the development of depressive symptoms in elderly. On the other hand, Toffanello et al. (13), in a prospectively studied population (Pro.V.A. study), showed that there was no direct effect between vitamin D deficiency and the onset of late-life depressive symptoms.

The oldest old people are not included or are underrepresented in most of the studies. Because of that, we want to know if there is association between depressive symptoms and vitamin D in elderly aged 80 and over who are physically more active and independent. 
Table 1

Characterization of elderly aged 80 years and over according to gender

\begin{tabular}{|c|c|c|c|}
\hline & Men (n=49) & Women $(n=133)$ & $\mathrm{p}$ \\
\hline Age, years, median (CI 95\%; IA) & $85,0(85,0-87,0 ; 6,0)$ & $85,0(84,0-86,0 ; 7,0)$ & $\mathrm{p}=0,651^{*}$ \\
\hline \multicolumn{4}{|l|}{ Ethnicity, n (\%) } \\
\hline white & $40(81,6)$ & $87(65,4)$ & \multirow[t]{3}{*}{$\mathrm{p}=0,096 \&$} \\
\hline black and mixed & $6(12,2)$ & $34(25,6)$ & \\
\hline asian & $3(6,1)$ & $12(9,0)$ & \\
\hline \multicolumn{4}{|l|}{$25(\mathrm{OH})$ Vit D, n $(\%)$} \\
\hline deficiency & $5(10,2)$ & $21(15,8)$ & \multirow[t]{3}{*}{$\mathrm{p}=0,466 \#$} \\
\hline insufficiency & $36(73,5)$ & $97(72,9)$ & \\
\hline sufficiency & $8(16,3)$ & $15(11,3)$ & \\
\hline Score on MMSE, median (CI 95\%; IA) & $26,0(24,0-26,0 ; 4,0)$ & $24,0(23,0-25,0 ; 5,0)$ & $\mathrm{p}=0,007^{* *}$ \\
\hline Score on GDS, median (CI 95\%; IA) & $3,0(2,0-4,0 ; 3,0)$ & $4,0(3,0-5,0 ; 3,0)$ & $\mathrm{p}=0,009^{* * *}$ \\
\hline BMIa, kg/m², median (CI 95\%; SD) & $26,7(25,4-28,0 ; 4,4)$ & $26,7(25,9-27,4 ; 4,4)$ & $\mathrm{p}=0,668^{* * * *}$ \\
\hline \multicolumn{4}{|l|}{ Smoking, n (\%) } \\
\hline current & $2(4,1)$ & $2(1,5)$ & \multirow[t]{3}{*}{$\mathrm{p}<0,001 \&$} \\
\hline previous & $31(63,3)$ & $22(16,5)$ & \\
\hline never smoked & $16(32,7)$ & $109(82,0)$ & \\
\hline
\end{tabular}

IA: interquartile amplitude; CI: confidence interval; SD: standard deviation; MMSE: Mini-mental state examination; GDS: Geriatric depression scale; BMI: Body mass index; Missing values a=9; * $\mathrm{U}=3116,50, \mathrm{z}=-0,452 ;{ }^{* *} \mathrm{U}=2399,00, \mathrm{z}=-2,678$; ${ }^{* *} \mathrm{U}=2444, \mathrm{z}=-2,605$; ${ }^{* * *} \mathrm{U}=2835,50, \mathrm{z}=-0,428$; \# X2=1,505, gl=2; \&Fisher's exact test.

\section{Methods}

\section{Studied population}

The analyzed data is part of a cohort study about free-living independent elderly aged 80 and over. The elderly have been following in the Geriatric Division from Federal University of São Paulo. We didn't include oldest old people with dementia, cancer, acute disease, dialytic therapy, chemotherapy or radiotherapy.

The studied population included 182 oldest old people evaluated from the period of January 2010 to January 2012. The experimental protocols were approved by the appropriate institutional review committee and meet the guidelines of their responsible governmental agency. Informed consent was obtained from all individual participants included in the study (Federal University of São Paulo Ethical Committee approval number 1532/09).

\section{Clinical assessment}

The collected data were sex, age, ethnicity, precedence, smoking history (current, previous or more than one year without smoking, never smoked), alcohol history (drinking any amount of alcohol in the last 10 years), health perception (excellent, good, regular or bad), chronic pain (presence of pain for more than 3 months), and any exposition to sunlight. The neuropsychological evaluation was made by the Mini-mental state examination (MMSE) developed by Folstein and validated in Brazil by Brucki et al. (14). The functionality was evaluated by the Instrumental activities of their daily living (IADL) (15). The nutritional evaluation was made by the means of the Body mass index (BMI) (16), abdominal circumference (AC - we considered as a high $A C$ value in elderly $\geq 102 \mathrm{~cm}$ in men and $\geq 88 \mathrm{~cm}$ in women), hip circumference (HC) and waist-to-hip ratio $(\mathrm{WHR}=\mathrm{CA} / \mathrm{HC}$; WHR $>0,99 \mathrm{~cm} 2$ in men or $>0,97$ in women is associated with an increased cardiovascular risk) (17).

The approach of the depressive symptoms was done by the Geriatric Depression Scale (GDS) in its reduced 15 item version. Paradela et al. (18) validated the Portuguese version of the GDS to track depressive symptoms in ambulatory elderly, with a cut mark at 5/6 showing sensibility of $81 \%$ and specificity of $71 \%$.

\section{Biochemical analysis}

The biochemical analysis of creatinine, fasting glycemia and serum hemoglobin was measured on a fasting blood specimens (collected after 10-hour fast). $25(\mathrm{OH})$ VitD analyses was done in serum sample refrigerated and protected from solar exposition. We used the DiaSorin LIAISON ${ }^{\circledR} 25(\mathrm{OH})$ VitD, which one is based on chemiluminescence technology (CLIA). 
Table 2

Characterization of elderly aged 80 years and over according to levels of 25(OH)Vit D

\begin{tabular}{|c|c|c|c|c|}
\hline & \multicolumn{4}{|c|}{ 25(OH)Vit D } \\
\hline & Deficiency & Insufficiency & Sufficiency & $\mathrm{p}$ \\
\hline Age, years, median, (CI 95\%; IA) & $86,5(85,0-90,0 ; 8,3)$ & $85,0(84,0-85,0 ; 7,0)$ & $86,0(83,0-87,0 ; 6,0)$ & $\mathrm{p}=0,064^{*}$ \\
\hline Female, n (\%) & $21(80,8)$ & $97(72,9)$ & $15(65,2)$ & $\mathrm{p}=0,471 \#$ \\
\hline Score on MMSE, median (CI 95\%; IA) & $23,0(20,5-25,0 ; 6,5)$ & $24,0(24,0-25,0 ; 4,5)$ & $24,0(22,0-26,0 ; 5,0)$ & $\mathrm{p}=0,463^{* *}$ \\
\hline Score on GDS, median (CI 95\%; IA) & $4,0(4,0-5,0 ; 3,5)$ & $4,0(3,0-4,0 ; 3,0)$ & $1,0(1,0-3,0 ; 4,0)$ & $\mathrm{p}=0,005^{* * *}$ \\
\hline BMIa, $\mathrm{kg} / \mathrm{m}^{2}$, average, (CI 95\%) & $26,2(24,4-28,0)$ & $26,9(26,2-27,7)$ & $25,7(23,9-27,5)$ & $\mathrm{p}=0,375^{* * * *}$ \\
\hline \multicolumn{5}{|l|}{ Abdominal circunference ${ }^{b} \mathrm{n}(\%)$} \\
\hline normal & $6(25,0)$ & $57(44,5)$ & $12(54,5)$ & $\mathrm{p}=0,106 \# \#$ \\
\hline increased & $18(75,0)$ & $71(55,5)$ & $10(45,5)$ & \\
\hline \multicolumn{5}{|l|}{ WHRc n $(\%)$} \\
\hline normal & $15(62,5)$ & $51(39,8)$ & $10(45,5)$ & $\mathrm{p}=0,119 \# \# \#$ \\
\hline increased & $9(37,5)$ & $77(60,2)$ & $12(54,5)$ & \\
\hline \multicolumn{5}{|l|}{ Smoking, n (\%) } \\
\hline current & $1(3,8)$ & $3(2,3)$ & $0(0,0)$ & $\mathrm{p}=0,787 \&$ \\
\hline previous & $6(23,1)$ & $39(29,3)$ & $8(34,8)$ & \\
\hline never smoked & $19(73,1)$ & $91(68,4)$ & $15(65,2)$ & \\
\hline Alcohol ingestion, $\mathrm{n}(\%)$ & $3(11,5)$ & $24(18,0)$ & $5(21,7)$ & $\mathrm{p}=0,629 \&$ \\
\hline $\begin{array}{l}\text { Clearance of creatinine } \mathrm{mL} / \mathrm{min} \text {, median } \\
\text { (CI 95\%; IA) }\end{array}$ & $42,0(33,4-47,6 ; 18,0)$ & $47,1(44,9-51,8 ; 18,0)$ & $40,4(37,6-48,2 ; 11,9)$ & $\mathrm{p}=0,011^{* * * * *}$ \\
\hline Hemoglobine, g/dL, average (CI 95\%; SD) & $13,0(12,6-13,4 ; 1,1)$ & $13,4(13,1-13,6 ; 1,2)$ & $13,3(12,5-14,2 ; 1,9)$ & $\mathrm{p}=0,289^{* * * * * *}$ \\
\hline
\end{tabular}

We considered deficiency serum level of $25(\mathrm{OH}) \mathrm{VitD}$ $<10 \mathrm{ng} / \mathrm{mL}$, insufficiency between 10 and $30 \mathrm{ng} / \mathrm{mL}$ and sufficiency $>30 \mathrm{ng} / \mathrm{mL}(10)$.

\section{Statistical analysis}

For data processing we used "Statistical Package for the Social Sciences (SPSS) for Windows" (version 13). A measure of central tendency was represented by median and interquartile amplitude (IA) when appropriate. We used the bootstrapping method for assigning confidence intervals from the proportion and median. Levene's test was used to assess the equality of variances for a variable calculated for two or more groups. We also used t Student's test to determine if two sets of data were significantly different from each other, and the non-parametric tests Mann-Whitney (U) and KruskalWallis (KW). When the Kruskal-Wallis (KW) test leads to significant results, Mann-Whitney (U)'s test was used with Bonferroni-corrected significance level. Chi-square test (X2) was used considering the recommendations of Cochran and the Fisher's exact test when these recommendations were violated.

\section{Results}

We studied independent oldest old people, with a IADL median 26,0 (IA 5,0) for men and 24,0 (IA 5,0) for women $(p=0,187)$. Most of them were women and $82 \%$ of oldest old women never smoked (Table 1). The women had more depressive symptoms than men. On the other hand, oldest old men had a better performance on MMSE, with a schooling median $4,0(\mathrm{IA}=5,5)$ for men and 3,0 (IA 3,3) for women ( $p=0,09)$. 83,7\% of men and $88,7 \%$ of women had insufficiency or deficiency blood levels of $25(\mathrm{OH})$ Vit D although 52,2\% declared sunlight exposition.

We also observed that $66,7 \%$ of men and $49,2 \%$ of women had excellent or good health perception $(p=0,154) .77,6 \%$ of men and $62,4 \%$ of women did not have chronic pain $(\mathrm{p}=0,076)$ and $36,2 \%$ of men and $64,6 \%$ of women had abdominal circumference increased $(\mathrm{X} 2=11,280 ; \mathrm{gl}=1, \mathrm{p}=0,001)$. There were no differences between serum levels of fasting glycemia of men 
compared to women (median $87,0+/-16,0$ and 88,0 $+/-17,0$ respectively). However, the men hemoglobin (average $13,7+/-1,6$ ) was greater than for women (average 13,2+/-1,5; $\mathrm{p}=0.005$ ).

According to blood level of 25(OH)Vit D (Table 2) we found difference between GDS score comparing the groups: "deficiency" $(U=144,50 ; z=-3,126 ; p=0,002)$ and "insufficiency" groups ( $U=975,50 ; z=-2,793 ; p=0.005)$ are different than "sufficiency" group; but there was no difference between "deficiency" and "insufficiency" groups $(U=1460,00 ; z=-1.263 ; p=0,206)$.

\section{Discussion}

In our cross-sectional study, we observed that there was association between worst GDS scores with < 30ng/ $\mathrm{mL}$ of $25(\mathrm{OH}) \mathrm{Vit} \mathrm{D}$ in oldest old people. It's already known that depressive symptoms are associated with clinical 25(OH)Vit D deficiency (levels $<10 \mathrm{ng} / \mathrm{mL}$ ) (19) in elderly 65 years of age. This was confirmed in a systematic review and meta-analysis of epidemiological studies: depression risk was found to be inversely associated with serum $25(\mathrm{OH}) \mathrm{Vit} \mathrm{D}$ in both crosssectional and cohort studies (20). But it seems that in freeliving independent oldest old people the goal of $25(\mathrm{OH})$ Vit $\mathrm{D}$ levels can be higher to avoid depressive symptoms, levels under 30ng/mL can be inadequate. We have to consider that there is a decline of $25(\mathrm{OH})$ Vit D levels with age and also a gender difference (21) that is going to increase the risk of depression in oldest old age and can compromise functionality.

Low blood levels of $25(\mathrm{OH})$ Vit D can be related with the inflammatory status observed in depressed patients, because in these conditions, auto-reactive $\mathrm{T}$ cells against tissues and synthesis of the interleukins and the proinflammatory cytokines (IL-12, interferon gama) are stimulated by the immunologic system (22). Synthesis and metabolism of serotonin (5-hydroxytryptamine) is influenced by cytokine signaling pathways (23). In physiologic conditions, indoleamine 2,3-dioxigenase (IDO) compete by tryptophan hydroxylase (TH) in tryptophan metabolism. The activation of IDO metabolizes the tryptophan in kynurenine and in the end quinolinic acid. It decreases brain tryptophan and the serotonin levels.

The functional reserve decline with age and also the capability to the oldest old to maintain a health life style and independency. It's interesting to note that these oldest old people are independent, free-living individuals and even so had 25(OH)Vit D levels under 30ng/mL. This was found for others researchers in elderly above 60 years of age $(24,25)$ despite their high sun exposure during the summer months and regarding the nutritional status (26).

It's suggested that $25(\mathrm{OH})$ Vit D supplementation is indicated as a complement of depression treatment (27).
Zanetidou et al. (28) demonstrated that administering $25(\mathrm{OH}) \mathrm{Vit} \mathrm{D}$ to patients 65 years or older as an adjunct to antidepressant therapy was associated with a significant improvement in the depressive symptomatology. Considering that the costs are low and side effects are not common, $25(\mathrm{OH})$ Vit D supplementation is very costeffective and can be a good choice to prevent depressive symptoms. This can be an important public health action to avoid depressive humor in oldest old people (29). We already know that to prevent fractures the goal is $>$ $30 \mathrm{ng} / \mathrm{mL}$ of $25(\mathrm{OH})$ Vit D (30) and it seems that, in oldest old people these levels are also recommended to avoid depressive symptoms. It's important to establish if to avoid depressive symptoms in oldest old the goal is also $>30 \mathrm{ng} / \mathrm{mL}$ of $25(\mathrm{OH})$ Vit D.

Our study has limitations: selection was by convenience and the GDS is a screening instrument and detect depression symptoms and not the diagnosis of depression. It's also important to note that $56,9 \%$ of the sample had an increased abdominal circumference that can be related with low levels of $25(\mathrm{OH}) \mathrm{Vit} \mathrm{D}$ and also with a more inflammatory condition.

We conclude that the goal of $25(\mathrm{OH})$ Vit D levels can be higher to avoid depressive symptoms in freeliving independent oldest old people and levels under $30 \mathrm{ng} / \mathrm{mL}$ can be inadequate. Considering that the costs are low and side effects are not common, 25(OH)Vit D supplementation can be an important public health action.

Funding: This study was funded by FAPESP (Fundação de Amparo à Pesquisa do Estado de São Paulo - São Paulo Research Funding Foundation) - grant number 2011/12753-8. The sponsors had no role in the design and conduct of the study; in the collection, analysis, and interpretation of data; in the preparation of the manuscript; or in the review or approval of the manuscript.

Acknowledgements: We acknowledge and thank Ana Beatriz Galhardi Di Tommaso, Renato Laks, Paulo Mateus Costa Affonso, and all doctors who contributed in data collection.

Conflict of interest: Márcio Tomita da Rocha Lima, Osvladir Custódio, Patricia Ferreira do Prado Moreira, Lara Miguel Quirino Araujo, Clineu de Mello Almada Filho and Maysa Seabra Cendoroglo have no conflicts of interest to declare.

Ethical standards: This experiment complies with the current laws of the country in which they were performed.

\section{References}

1. World Bank. Growing old in an older Brazil: implications of population aging on growth, poverty, public finance, and service delivery. 2011. https:// openknowledge.worldbank.org/bitstream/ handle / 10986 / 2351 / 644410PUB00Gro00ID0188020BOX361537B. pdf?sequence=1. Accessed 09 Dec 2015.

2. Snowdon J. How high is the prevalence of of depression in old age? Rev Bras Psiquiatr 2002;24(Suppl. I):42-47. http: / dx.doi.org/10.1590/S151644462002000500009. Accessed 11 August 2015.

3. Blay SL, Andreoli SB, Fillenbaum GG, Gastal FL. Depression morbidity in later life: prevalence and correlates in a developing country. Am J Geriatric Psychiatry 2007;15(9):790-799.

4. Diniz BS, Reynolds CF 3rd, Butters MA, et al. The effect of gender, age, and symptom severity in late-life depression on the risk of all-cause mortality: The Bamuí Cohort Study of Aging. Depress Anxiety 2014;31(9):787-795.

5. Jeon HS, Dunkle RE. Stress and depression among the oldest-old: A longitudinal analysis. Res Aging 2009;31(6):661-687.

6. Wu Z, Schimmele CM, Chappell NL. Aging and late-life depression. J Aging Health 2012;24(1):3-28. 
7. Weyerer S, Eifflaender-Gorfer S, Wiese B, et al. Incidence and predictors of depression in non-demented primary care attenders aged 75 years and older: results from a 3-year follow-up study. Age and Ageing 2013;42(2):173-180.

8. Alexandre Tda S, Corona LP, Nunes DP, Santos JL, Duarte YA, Lebrão ML. Gender differences in incidence and determinants of disability in activities of daily living among elderly individuals: SABE study. Arch Gerontol Geriatr 2012;55(2):431-437.

9. Boyle LL, Porsteinsson AP, Cui X, King DA, Lyness JM. Depression predicts cognitive disorders in older primary care patients. J Clin Psychiatry 2010;71(1):74-79.

10. Holick MF. Vitamin D deficiency. N Engl J Med 2007;357:266-281.

11. Hoogendijk WJ, Lips P, Dik MG, Deeg DJ, Beekman AT, Penninx BW. Depression is associated with decreased 25-hydroxyvitamin D and increased parathyroid hormone levels in older adults. Arch Gen Psychiatry 2008;65(5):508-512.

12. Milaneschi Y, Shardell M, Corsi AM, et al. Serum 25-hydroxyvitamin D and depressive symptoms in older women and men. J Clin Endocrinol Metab 2010;95(7):3225-3233.

13. Toffanello ED, Sergi G, Veronese N. Serum 25-hydroxyvitamin d and the onset of late-life depressive mood in older men and women: the Pro.V.A. study. J Gerontol A Biol Sci Med Sci 2014;69(12):1554-1561.

14. Brucki SM, Nitrini R, Caramelli P, Bertolucci PH, Okamoto IH. Suggestions for utilization of the mini-mental state examination in Brazil. Arq Neuropsiquiatr 2003;61(3B):777-781.

15. Lawton MP, Brody EM. Assessment of older people: self-maintaining and instrumental activities of daily living. Gerontologist 1969;9:179-186.

16. Lipschitz DA. Screening for nutritional status in the elderly. Prim Care 1994;21:55-67.

17. Gravina CF, Franken R, Wenger N, et al. II Guidelines of Brazilian Society of Cardiology in geriatric cardiology. Arq Bras Cardiol 2010;95(3 supl.2):1-112 http: / / www.scielo.br/pdf/abc/v95n3s2/v95n3s2.pdf. Accessed 09 Dec 2015

18. Paradela EM, Lourenço RA, Veras RP. Validation of geriatric depression scale in a general outpatient clinic. Rev Saude Publica 2005;39(6):918-923.

19. Stewart R, Hirani V. Relationship between vitamin D levels and depressive symptoms in older residents from a national survey population. Psychosom Med 2010; 72(7):608-612.

20. Ju SY, Lee YJ, Jeong SN. Serum 25-hydroxyvitamin D levels and the risk of depression: a systematic review and meta-analysis. J Nutr Health Aging 2013;17(5):447-455

21. Hirani V, Primatesta P. Vitamin D concentrations among people aged 65 years and over living in private households and institutions in England: population survey. Age Ageing 2005;34(5):485-491.

22. Castro LC. The vitamin D endocrine system. Arq Bras Endocrinol Metab 2011;55(8):566-575.

23. Shelton RC, Miller AH. Eating ourselves to death (and despair): the contribution of adiposity and inflammation to depression. Prog Neurobiol 2010;91(4):275-299.

24. Saraiva GL, Cendoroglo MS, Ramos LR, et al. Prevalence of vitamin D deficiency, insufficiency and secondary hyperparathyroidism in the elderly inpatients and living in the community of the city of São Paulo, Brazil. Arq Bras Endocrinol Metab 2007;51(3):437-442.

25. Cabral MA, Borges CN, Maia JM, Aires CA, Bandeira F. Prevalence of vitamin D deficiency during the summer and its relationship with sun exposure and skin phototype in elderly men living in the tropics. Clin Interv Aging 2013;8:1347-1351.

26. Martini LA, Verly E Jr, Marchioni DM, Fisberg RM. Prevalence and correlates of calcium and vitamin D status adequacy in adolescents, adults, and elderly from the Health Survey-São Paulo. Nutrition 2013;29(6):845-850.

27. Berk M, Sanders KM, Pasco JA, et al. Vitamin D deficiency may play a role in depression. Medical Hypotheses 2007;69(6):1316-1319.

28. Zanetidou S, Belvederi Murri M, Buffa A, Malavolta N, Anzivino F, Bertakis K. Vitamin D supplements in geriatric major depression. Int J Geriatr Psychiatry 2011;26(11):1209-1210.

29. Young SN. Has the time come for clinical trials on the antidepressant effect of vitamin D? J Psychiatry Neurosci 2009;34(1):3.

30. Holick MF, Binkley NC, Bischoff-Ferrari HA, et al. Endocrine Society. Evaluation, treatment, and prevention of vitamin D deficiency: an Endocrine Society clinical practice guideline. J Clin Endocrinol Metab 2011;96(7):19111930. 